underprescribing could be occurring as well as overprescribing. In due course the district health authorities will be able to produce the referral, admission, and investigation rates for individual general practitioners, which again will be indicators rather than targets. As already seen in prescribing analysis and cost data interpretation of these figures is reliable only at the practice level and may be unreliable for individual doctors because of recording errors and variations in workload and case mix. We do now have a defined target for cervical cytology (table II) as well as the long established target of $90 \%$ for childhood immunisation.
These indicators and targets comprise a contractual audit. Unfortunately general practitioners may be so occupied meeting their obligations under this audit that they will not appreciate the difference between it and audit led by the profession, the most important part of which is considering the results and learning how to improve, and this is best done in an educational setting. Recording data should be part of routine care provision and gathering data for analysis delegated whenever possible, leaving interpretation to general practitioners. The dramatic increase in the use of computers for clinical recording makes this the most valuable tool for future audit.

\title{
Contribution of regional specialty subcommittees to organising audit
}

\author{
C D Collins
}

Hospital medical staff are now prepared to talk about, discuss, and criticise audit, but as yet little has been achieved, except by individual enthusiasts. For audit to be properly conducted and effective a considerable change is needed in attitudes of consultants. Such change requires guidance and encouragement; the royal colleges and faculties have offered general guidelines and the government has provided a timetable, requiring all consultants to be involved in medical audit by $1991 .^{\prime}$ It is, however, a big step from the receipt of such guidelines to detailed implementation of audit by individual consultants. Most district specialties lack an enthusiast to offer leadership in audit, and many specialties have too few members to permit a meaningful comparison of activity. Audit within specialties is therefore probably most effectively coordinated, if not organised, on a regional basis, as has been shown over the past few years by the Lothian surgical audit.

Regional specialist advisory commitees can bridge the gap between college guidelines and individual district or specialist audit activities. To be effective such committees must assume and be given by their colleagues responsibility as the peer group from whom guidance and leadership may be obtained in the setting up, conduct, and practice of audit. The organisation of such committees is important, with regard to their membership and their relation with each other, regional management, and individual consultants. One example of how this might be achieved is currently in practice in the South Western region.

The South Western regional hospital medical advisory committee is composed of a consultant nominated by each of the 11 districts and selected, as far as possible, from different specialties, the postgraduate dean, and a university representative, currently the professor of community medicine. The regional medical officer and his senior medical assistant attend regularly, and the regional manager attends when possible. The committee has called on skill from the King's Fund to assist it and its subcommittees in developing medical audit; it assumed this responsibility in the region almost a year before the white paper was published and acts as the regional audit committee. It circulated its guidelines The Regional Approach to Medical Audit in June 1989. Through the participation of the regional manager, and access, therefore, to the management network, it is possible to bring pressure on district and unit managements to provide facilities and support necessary for the proper conduct of audit.
In the south west the regional primary health care committee links general practitioners in the district into a regional audit framework and provides guidance and coordination to the district audit committees. It also has an important role in promoting dialogue between both sides of the hospital-primary care interface and fostering an understanding by each of the perceptions and priorities of the other; these are not always obvious and may stimulate the identification of certain useful outcome indicators. The regional hospital medical advisory committee has been concerned with $(a)$ development of software for audit; $(b)$ establishing the extent of support of administrative and clerical staff for the clinical teams; $(c)$ arranging for consultants to have sufficient sessional time to carry out audit; $(d)$ organising training for doctors concerned with setting up and initiating audit; and $(e)$ setting up regional arrangements for medical audit in specialties with only a few consultants in each district, through appropriate subcommittees. The role of regional specialty subcommittees varies with the number of consultants in each specialty. Those of the larger clinical specialties, such as general surgery, medicine, and trauma and orthopaedics, monitor, encourage, and coordinate the district audit activities. The smaller subcommittees either act as specialist audit committees in their own right or coordinate the activities of two or three subregional groups of consultants.

\section{Audit in general surgery}

In general surgery there are already several enthusiastic auditors whose skill may be harnessed and who might act as leaders in the organisation and practice of audit in their districts. For maximum effect the membership of a regional general surgical subcommittee should include a member from each district, preferably with management, educational, or audit responsibilities or experience, an expert audit adviser, a health care evaluator, a representative of the postgraduate dean or university, and a senior member of regional management plus secretarial support. A committee so constituted might then be able to gain the confidence of all the consultants in the specialty and offer guidance and specific proposals on the conduct of audit, both of the process and of the outcome of surgery. Such a committee must deal with several problems.

Attitude of consultants-Consultants' attitudes towards audit might be encouraged and developed by a combination of carrot and stick; for surgeons the stick 


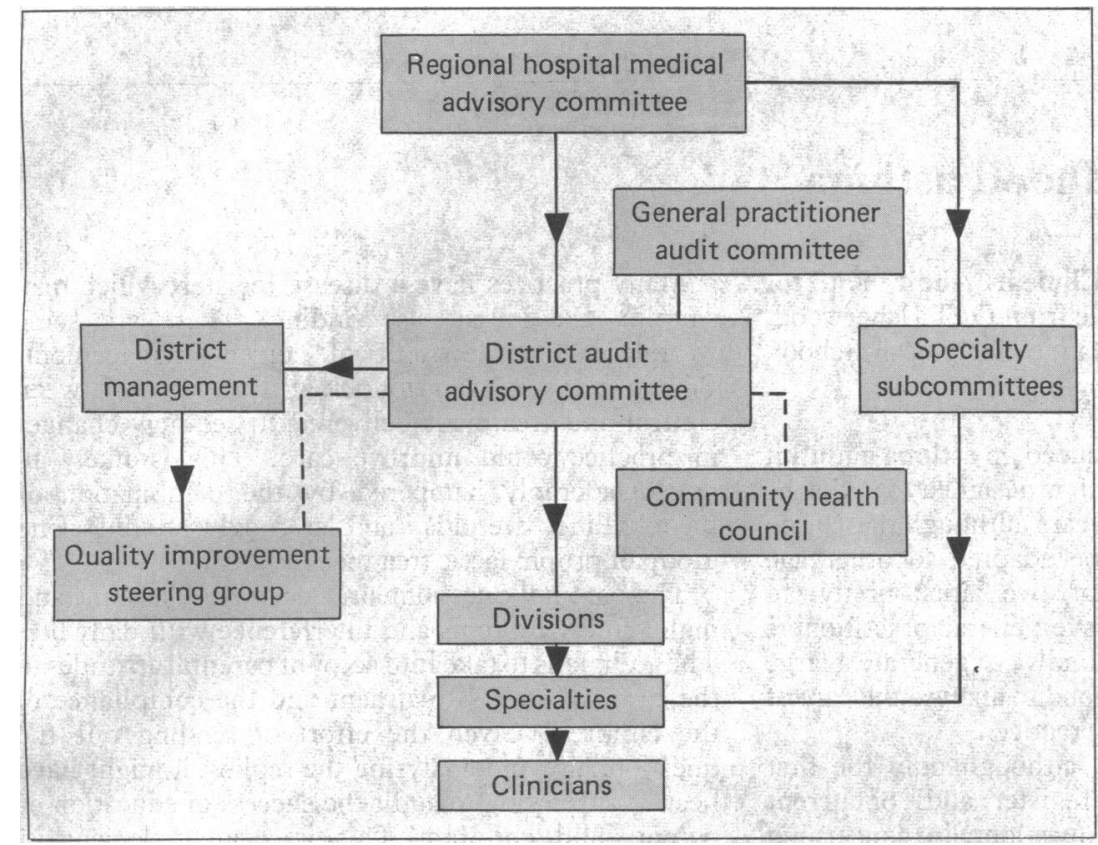

Regional audit structure complexity of the procedures undertaken. For audit it is essential to agree on both. The clinical severity index used in the confidential inquiry into perioperative deaths was that of the American Society of Anesthesiologists. This is currently used in the South Western regional pilot medical data index scheme. The American Medisgrps system is currently being evaluated in Bristol. Operative complexity has usually been assessed using the British United Provident Association (BUPA) scale, although a modification of the new BMA scale might become more generally acceptable. Regional, if not national, agreement on these two quality factors is being sought.

Assessment of surgical outcome-Much of the current medical reporting is devoted to that of individual short or long term follow up studies, many of which would be greatly strengthened by expansion to include different units in the region. Such coordination may be organised through the regional specialty subcommittees. Similarly standardised assessments of outcome may be agreed with the help of health care evaluation skills, academic input, and administrative support.

Identification and organisation of supradistrict specialist surgical services-The confidential inquiry into perioperative deaths and the Lothian audit have indicated the benefit to patients of allocating the care of less common conditions to experienced specialists. Districts cannot expect to offer the highest quality of care in every sphere of surgical activity. The strengths of individual surgical units for certain specialist activities should therefore be identified and recognised by the regional committees so that recommendations may be made for resources to be set aside to foster and develop suitable skill. Examples include renal transplantation, hepatic resection surgery and possibly oesophageal surgery, laser treatment, and the development of specialised endoscopic procedures. Such activities could be centred in any district general hospital where the specialised interest and skills of consultants are available.

Regional surgical audit report-A regional surgical audit report might comprise a brief amalgamation of individual district audit reports, and would promote the enthusiasm and the industry put into audit by providing a goal for individual district surgical audit committees. Effective changes in practice in one or other district would be highlighted and might then be coordinated into formulating regional management advice. Alternatively, conflicts in practice between districts might become a subject for audit by the regional specialist subcommittee itself.

All these audit functions require administrative, secretarial, and technological resources, which must be made available if the laudable aims of medical audit are to be achieved.

In conclusion, regional specialist advisory committees have an important part to play in the development and conduct of medical audit and have a special advantage in that consultants generally feel accountable to the region as their contract holder and will more readily accept advice from the region than that emanating from the district or unit, which they think is often guided more by resource implication than by the desire for improved clinical service. They may call on the resources of the health authority and the university, the royal colleges, and on specialist advice for help in coordinating and formulating policies and reports. By setting timetables and posing specific questions regional specialty subcommittees may help to implement the policies of the royal colleges and the Department of Health on the practice of medical audit.

\footnotetext{
1 Secretaries of State for Health, Wales, Northern Ireland, and Scotland. Workin for patients. London: HMSO, 1989. (Cmd 555 .

2 Royal College of Surgeons of England. Guidelines to clinical audit in surgical practice. London: RCS, 1989.
}

enent on severity and complexity coding - Curre NHS performance indicators permit comparison of the number of patient episodes, operations, discharges of the clinical severity of the patient's condition or the 